\title{
Fine needle aspiration cytology of thyroid and its correlation with serological findings
}

\author{
Karki S ${ }^{1}$, Shrestha $\mathrm{A}^{1}$ \\ ${ }^{I}$ Department of pathology, Tribhuvan University Teaching Hospital, Maharjagunj, Nepal
}

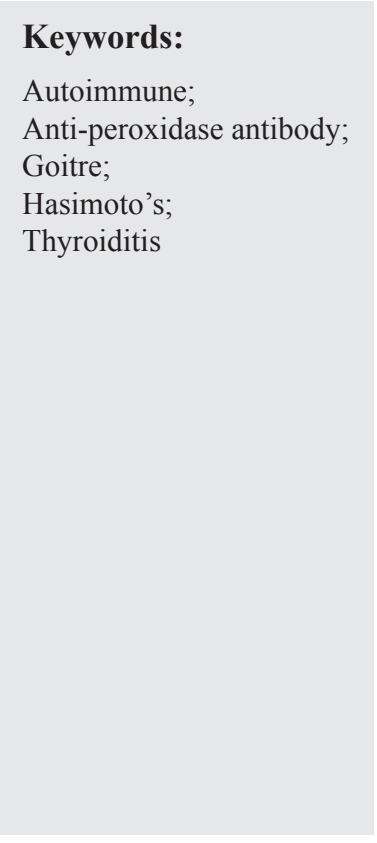

\begin{abstract}
Background: Thyroid autoimmunity can cause several forms of thyroid disorders i.e. Grave's disease, Hashimoto's thyroiditis, atrophic autoimmune thyroiditis, post-partum thyroidits etc. Cytological diagnosis may be sometimes difficult is some cases. In such conditions, cytology along with serological tests aid at reaching a correct diagnosis. Hence, this study was undertaken to evaluate the serum level of anti-TPO antibody with respect to serum concentrations of thyroid hormones and its importance in diagnosing autoimmune thyroiditis.
\end{abstract}

Materials and Methods: This study was carried out in the department of pathology from June 2013May 2014. Patients coming to the department of pathology TUTH, Maharajgunj for FNA of thyroid were included. TFT level was noted and anti TPO antibody level was evaluated by CLIA.

Results: Ninety-five thyroid FNAC was included in the study, which comprises of $16.8 \%$ males and $83.2 \%$ females with a M: F 1: 4.9. Maximum number of cases was seen in the age range 21-30 years (25.3\%), mean age being 40.4years. The cytological diagnosis comprised colloid goiter(43.2\%), lymphocytic thyroiditis(25.3\%), Hashimoto thyroiditis(18.9\%). Out of 42 cases of autoimmune thyroiditis diagnosed cytologically, $16(38 \%)$ were hypothyroid, 4 (9.5\%) hyperthyroid, 8 (19\%) sub-clinical hypothyroid and $14(33.5 \%)$ were euthyroid. The sensitivity and specificity of positive anti TPO in correctly identifying autoimmune thyroiditis was $85.7 \%$ and $79.2 \%$ respectively. The positive and negative predictive value for the test was $76.5 \%$ and $87.5 \%$ respectively.

Conclusion: Nodular goitre can harbour a certain percent of autoimmune thyroiditis and in such cases anti TPO antibody level along with cytodiagnosis appears to be helpful.

\section{INTRODUCTION}

There are various causes of goiter including iodine deficiency, ageing and autoimmune disease. ${ }^{1}$ Age related increase in the weight and nodularity of the gland may

\footnotetext{
Correspondence:

Dr. Shovana Karki, MBBS, MD

Lecturer, Department of Pathology

Tribhuvan University Teaching Hospital, Maharjagunj, Nepal.

Email:shovana_karki@hotmail.com
}

be due to iodine deficiency rather than an inherent ageing effect of the gland. ${ }^{2}$ Endemic goiters secondary to iodine deficiency is due to overstimulation of the thyroid by thyroid stimulating hormone (TSH). ${ }^{3}$

Other causes of nodular goiter are autoimmune thyroid disease. Thyroid autoimmunity can lead to multiple forms of thyroid disorders i.e. Grave's disease, Hashimoto's thyroiditis, atrophic autoimmune thyroiditis, post-partum 
Table 1: The cytological diagnosis along with clinical finding in thyroid.

\begin{tabular}{lcccc}
\hline \multicolumn{1}{c}{ FNAC diagnosis } & Clinical finding & Total (\%) \\
\hline Colloid goiter & Solitary & Multinodular & Diffuse \\
\hline Lymphocytic thyroiditis & 22 & 6 & 13 & $41(43.2 \%)$ \\
\hline Hashimoto thyroiditis & 3 & 2 & 19 & $24(25.3 \%)$ \\
\hline Papillary carcinoma & 3 & 2 & 13 & $18(18.9 \%)$ \\
\hline Follicular neoplasm & 5 & 0 & 0 & $5(5.2 \%)$ \\
\hline Hyperplastic goiter & 3 & 0 & 0 & $3(3.2 \%)$ \\
\hline De Quarvain thyroiditis & 0 & 0 & 2 & $2(2.1 \%)$ \\
\hline Total & 0 & 0 & 2 & $2(2.1 \%)$ \\
\hline
\end{tabular}

thyroidits etc. ${ }^{4}$ Amongst all these, Hashimoto's thyroiditis and Grave's disease are the commonest and these share many features immunologically. ${ }^{5,6}$

Anti-thyroid peroxidase (TPO) is an important diagnostic tool in autoimmune thyroid disease. ${ }^{7}$ Anti-TPO antibodies are more likely to be of pathogenetic importance because of the fact that:

1. They fix complement and may directly damage the thyroid cells. ${ }^{8}$

2. Serum anti-TPO antibody concentrations are positively correlated with the activity of chronic autoimmune thyroiditis. ${ }^{9}$

3. Greater number of patients with thyroiditis have high serum anti-TPO than anti-thyroglobulin antibody. ${ }^{10}$

4. Anti-TPO antibodies are cytotoxic in-vitro, as detected by antibody dependant cell cytotoxicity tests (ADCC). ${ }^{11}$

The gold standard for the diagnosis of Hashimoto's thyroiditis (chronic lymphocytic thyroidits) is cytological or histological. However in some cases the cytological findings can be confused with lymphocytic thyroidits or differential diagnosis between Hashimoto's thyroiditis and hyperplastic Hurtle cell nodules or Hurthle cell tumors is impossible. ${ }^{12}$ In these cases, a careful assessment of cytology along with serological tests is important in reaching a correct diagnosis.

Hence, this study was undertaken to evaluate the serum level of anti-TPO antibody with respect to serum concentrations of thyroid hormones and its importance in diagnosing autoimmune thyroiditis, especially Hashimoto's thyroiditis.

\section{MATERIALS AND METHODS}

This study was carried out in the department of pathology from June 2013-May 2014. Patients coming to the department of pathology TUTH, Maharajgunj for FNA
Table 2: The cytodiagnosis in patients with positive and negative anti TPO.

\begin{tabular}{lccl}
\hline \multicolumn{3}{c}{ FNA Diagnosis } \\
\hline Anti TPO & $\begin{array}{l}\text { Autoimmune } \\
\text { thyroiditis }\end{array}$ & Others & Total \\
\hline Positive & $36(\mathrm{TP})$ & $11(\mathrm{FP})$ & $47(49.5 \%)$ \\
\hline Negative & $6(\mathrm{FN})$ & $42(\mathrm{TN})$ & $48(50.5 \%)$ \\
\hline Total & $42(44.2 \%)$ & $53(55.8 \%)$ & $95(100 \%)$ \\
\hline
\end{tabular}

of thyroid were included. Permission was obtained from institutional review committee. FNAC was performed using aseptic precaution using $10 \mathrm{ml}$ sterile syringe with 23 gauge needle. One slide was kept in absolute alcohol and other was air-dried. The slides were stained with Papanicolaou stain and Wright stain. Diagnosis was made by consultant pathologist. Thyroid function test was done in all patients and anti TPO antibody level was evaluated by chemiluminiscence immunoassay. Statistical analysis was performed using SPSS 16.

\section{RESULTS}

A total of 95 thyroid FNACs included in the study consisted of $16.8 \%$ males (16 cases) and $83.2 \%$ females (79 cases) with male to female ratio 1: 4.9. Maximum number of cases was seen in the age range 21-30 years (25.3\%) followed by $31-40$ years $(24.2 \%)$. Mean age of the patient with thyroid lesion was $40.4 y e a r s$. The cytological diagnosis consisted predominantly of colloid goiter 41 cases $(43.2 \%)$ followed by lymphocytic thyroiditis 24 cases $(25.3 \%)$ and Hashimoto thyroiditis 18 cases $(18.9 \%)$. Other cases included papillary carcinoma, hyperplastic goiter, follicular neoplasm and De Quarvian's thyroiditis (Table 1).

Nineteen cases of lymphocytic thyroiditis and 13 cases of Hashimoto thyroiditis presented as diffuse thyroid swelling whereas 3 cases of each presented as solitary nodule. Out of 42 cases of autoimmune thyroiditis diagnosed cytologically, 16 (38\%) were clinically hypothyroid, 4 (9.5\%) hyperthyroid, 8 (19\%) sub-clinical hypothyroid 


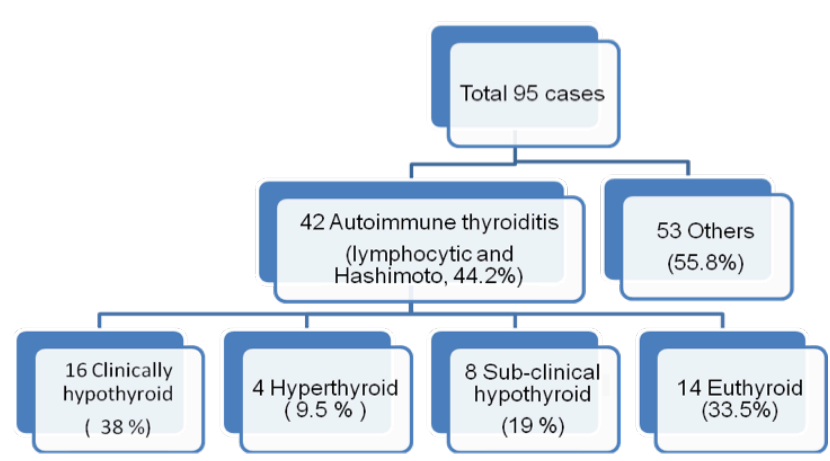

Figure 1: Distribution of cytologically diagnosed cases based on thyroid function test

and 14 (33.5\%) were euthyroid (fig.1). Out of 95 cases, 47 cases $(49.5 \%)$ had high anti TPO level whereas 48 cases (50.5\%) showed normal anti TPO level. Cytologically proven autoimmune thyroiditis was 42 cases. The result in Table 2 indicates that the sensitivity and specificity of positive anti TPO in correctly identifying autoimmune thyroiditis was $85.7 \%$ and $79.2 \%$ respectively. The positive and negative predictive value for the test was $76.5 \%$ and $87.5 \%$ respectively. The area under the ROC curve is 0.90 . By lowering the cut off threshold to $6 \mathrm{IU} / \mathrm{L}$ the sensitivity of the test can be raised to $92.9 \%$ (fig. 2). Histopathology of 24 cases was received. Twenty cases diagnosed as colloid goitre on FNA proved to be colloid goitre on biopsy. The remaining four cases diagnosed as papillary carcinoma on FNA showed papillary carcinoma with one case showing Hashimoto's thyroiditis in the adjacent tissue. This particular case had elevated anti-TPO level.

\section{DISCUSSION}

In the general population, goitre accounts for $4-10 \%$ of cases. Malignancy being rare in the thyroid accounts for $3-11 \%$ of goitres. Remainder represents benign lesions of the thyroid. ${ }^{13}$ So the clinical challenge lies in pre-operative identification of malignant lesions so that the indication for surgery in benign lesions can be minimized.

As with other studies, a female predominance was seen in patients with thyroid lesion in this study as well.1 The mean age at presentation was 40.4 years which is similar to a study carried out by Staii et al. ${ }^{14}$

The cytological diagnosis of autoimmune thyroiditis (fig. 3 \&4) was made in $44.2 \%$ comprising 42 cases ( 24 lymphocytic thyroiditis and 18 Hashimoto thyroiditis). Autoimmune thyroiditis is diagnosed in about $3 \%$ of population with the prevalence increasing in older women upto $16 \%{ }^{1}$ But the prevalence of the disease varies depending on the diagnostic methods used and the population under study. A study by Chehade et al showed autoimmune thyroiditis in $35.4 \%$ of cases. ${ }^{1}$
Solitary nodule in the thyroid was seen in $14 \%$ of the cases of autoimmune thyroiditis (3 cases each of lymphocytic thyroiditis and Hashimoto thyroiditis). 9.5\% presented as multinodular goitre and the rest as diffuse goitre. Other studies also stated that autoimmune thyroiditis is a common finding in nodular goiter. ${ }^{1}$ This finding highlights the importance of routine screening of anti TPO antibodies along with TSH levels in a patient with nodular goitre.

Among the patients with autoimmune thyroiditis $38 \%$ were clinically hypothyroid, 19\% subclinical hypothyroid whereas $33.5 \%$ were euthyroid as determined by the TFT level. Majority of the patients with chronic lymphocytic thyroiditis were euthyroid in a study by Staii et al. ${ }^{14}$ Subclinical and clinical hypothyroidism is associated with cardiovascular and neuropsychiatric morbidities. Hence, detection of autoimmune thyroiditis in nodular goitre becomes clinically significant. ${ }^{15-16}$

As with other studies, ${ }^{14}$ an important aspect of this study is that most patients with autoimmune thyroiditis were pre-menopausal females with high TSH levels. The risk of miscarriage, fetal and neonatal death increases with higher TSH levels. ${ }^{17-18}$ The risk of fetal loss was found even when maternal FT3 was normal. ${ }^{17}$ Based on the result of high number of cytologically proven autoimmune thyroiditis with a significant number of euthyroid disease, a follow up TFT in these cases from pre-conception to delivery stages may be indicated.

Inflammation of the thyroid epithelium leads to tissue remodeling in autoimmune thyroiditis and the possibility of acquiring mutations while cells are dividing is greater. Studies have shown that inflammation of the thyroid could be linked to cancer. ${ }^{19-20}$

Anti TPO had a sensitivity and specificity of $85.7 \%$ and $79.2 \%$, respectively in diagnosing autoimmune thyroiditis.

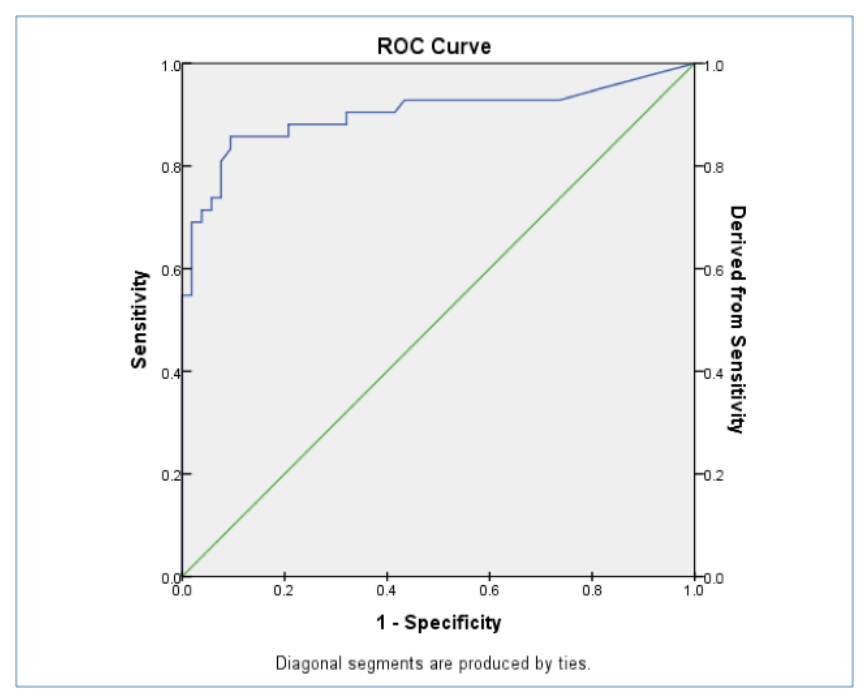

Figure 2: ROC curve of Anti TPO 
This highlights the importance of routine screening of anti TPO antibody and TSH level in the setting of goitre. Studies suggest that more than $50 \%$ of the clinicians order anti TPO antibody testing in the evaluation of goiter.1 This study may be helpful is increasing the use of anti TPO level in the evaluation of goitre.

In a study by Engler et al, the highest frequency of anti TPO positivity was seen in autoimmune thyroiditis $88 \%$ followed by patients with Grave's disease $53 \% .{ }^{21}$ Sensitivity of $96 \%$ was seen in Hashimoto's thyroiditis.

This study found elevated anti TPO antibody in colloid goiter ( 4 cases), papillary carcinoma ( 3 cases), hyperplastic nodule ( 2 cases) and follicular neoplasm ( 2 cases). A single case of papillary carcinoma with elevated anti TPO level showed Hashimoto thyroiditis in the adjacent tissue on biopsy. Anti TPO expression level when tested on papillary, follicular and anaplastic carcinoma by Rebuffet et $\mathrm{al}^{22}$ found that TPO was present on all cell lines but it was less expressed in follicular and anaplastic carcinoma when compared with papillary carcinoma. Similar finding was seen in a study by Bera et al. ${ }^{18}$ However, no significant difference in the level of anti TPO was observed in follicular adenoma and carcinoma in the same study. Hence, immunological bases in the development of papillary carcinoma may be considered a primary field.

On USG, diffuse thyroiditis is diagnosed by decreased echogenicity and micronodules which have a PPV of 95\%.23 Whereas most nodular thyroiditis nodules are solid but a substantial minority can have cystic components and calcification which makes radiological diagnosis difficult.24 Hence, in cases of nodular goitre which can contain a certain percent of autoimmune thyroiditis anti TPO antibody level along with cytodiagnosis appears to be helpful.

\section{CONCLUSION}

Anti TPO level is elevated in case of autoimmune thyroiditis. In cases of nodular goitre which can contain a certain percent of autoimmune thyroiditis anti TPO antibody level along with cytodiagnosis appears to be helpful.

\section{REFERENCES}

1. Chehade JM, Lim W, Silverberg AB, Mooradian AD. The incidence of Hashimoto's disease in nodular goiter: the concordance in serological and cytological findings, Int J Clin Pract 2010;64:29-33. Crossref

2. Laurberg P, Pedersen KM, A Hreidarsson et al. Iodine intake and the pattern of thyroid disorders: a comparative epidemiological study of thyroid abnormalities in the elderly in Iceland and in Jutland Denmark. J Clin Endocrinal Metab 1998;89:765-9. Crossref

3. Kollur SM, El Sayed S, El Hag IA. Follicular thyroid lesions co- existing with Hashimoto's thyroidits: incidence and possible sources of diagnostic errors. Diagn Cytopathol 2003;28:35-8. Crossref

4. Ghoraishian SM, Moghaddam SHH, Afkhami M. Relationship between anti-thyroid peroxidase antibody and thyroid function tests. World J Med Sci 2006;1:44-7.

5. Larry J, Weetman AP. Disorders of thyroid gland, In: Brunwald, E, A Fauci. Harrison's Principles of Internal Medicine 15th Ed. Vol 2, McGraw-Hill Publication: Philadelphia; 2001. Pp 2060-84. Crossref

6. Marcocci C, Chiovato L, 2000. Thyroid - directed antibodies. In : Braverman, LE and R.D. Utiger. The thyroid : A fundamental and clinical text 8 th edition. Williams and Wilkins: Philadelphia;200. Pp414-31.

7. Kotani T. Anti - TPO autoantibodies. Rinsho Byori 1998;46:324-30. Crossref

8. Guo J. Jaume JC, Rapoport B et al. R ecombinant thyroid peroxidase - specific Fab converted to immunoglobulin G (IgG) molecules : evidence for thyroid cell damage by IgG1, but not IgG4, autoantibodies J. Clin. Endocrinol. Metab. 1997;82:925-31. Crossref

9. Yoshida H, Amiro N, Yagawa K. Association of serum antithyroid antibodies with lymphocytic infiltration of the thyroid gland : studies of seventy autopsied cases. J. Cliln. Endocrinol. Met 1987;46:85962. Crossref

10. Mariotti S, Anelli S, Ruf J. Comparision of serum thyroid microsomal and thyroid peroxidase autoantibodies in thyroid disease. J Clin Endocrinal 1987;65:987-93. Crossref

11. Raspe E, Costagliola S, Ruf J. Identification of the $\mathrm{Na}+/ \mathrm{I}-$ cotransporter as a potential autoantigen in thyroid autoimmune disease. Eur. J. Endocrinol 1995;132:399-405. Crossref

12. Gull WW: On a cretinoid state supervening in adult life in women. Transactions of the Clinical Society of London 1873;7:180-5.

13. Kumar S, Aquil S, Dahar A. Role of fine needle aspiration cytology in thyroid diseases. Int J Surg 2008;13:22-5.

14. Staii A, Mirocha S, Todorova-koteva K, Glinberg S, Jaume JC. Hashimoto thyroiditis is more frequent than expected when diagnosed by cytology which uncovers a pre-clinical state. Thyroid research 2010; 3:11. Crossref

15. Surks MI, Ocampo E. Subclinical thyroid disease. Am J Med 1986;100:217-23. Crossref

16. Helfand M, Redfern LC. Screening for thyroid disease: an update. Ann Intern Med 1998;129:144-58. Crossref

17. Benhadi N, Wiersinga WM, Reitsma JB, Virjkotte TG, Bonsel GJ. Higher maternal TSH levels in pregnancy are associated with increased risk for miscarriage, fetal or neonatal death. Eur J 
Endocrinol2009; 160:985-991. Crossref

18. Haddow JE, Palomaki GE, Williams JR, et al. Maternal thyroid deficiency and pregnancy complications: implications for population screening. J Med Screen 2000;7:127-30. Crossref

19. Larson SD, Jackson I, Riall Ts, et al. Increase of well differentiated thyroid cancer associated with Hashimoto thyroiditis and the role of the PI3K/AKT pathway. J Am Coll Surg 2007;204:764-73. Crossref

20. Borrello MG, Alberti L, Fischer A, Deglinnocenti D, Ferrario C, Gariboldi $\mathrm{M}$ et al. Inducation of a proinflammatory program in normal human thyrocytes by the RET/PTC1 incogene. Proc Natl Acad Sci USA 2005;102:14825-30. Crossref

21. Engler H, Riesen WF, Keller B. Anti-thyroid peroxidise antibodies in thyroid diseases, non-thyroidal illness and controls. Clinical validity of a new commercial method for detection of anti-TPO antibodies. Clin Chem Acta 1994;225:123-36. Crossref
22. Rebuffat SA, Morin M, Nguyen B, Casrex F, Robert B, Peraldi-Roux S. Human recombinant anti-thyroperoxidase antibodies in vitro cytotoxic activity on papillary thyroid carcinoma expressing TPO. Br. J. Cancer 2010; 102:852-61. Crossref

23. Bera S, Gupta S, Dutta SK, Choudary KM, Bhattacharya S, Saha M. Anti-thyroid peroxidise antibody level in thyroid nodules: with special reference to thyroid neoplasia. Int J. Pharm 2013;4:150-2.

24. Anderson L, Middleton WD, Teefey SA, Reading CC, Langer JE, Desser $\mathrm{T}$ et al. Hashimoto Thyroiditis: Part 1, sonographic analysis of the nodular form of hashimoto thyroiditis. Am J Roentgenol 2010;195:208-15. Crossref 